\title{
Removal of Heavy Metals by Biosorption Technique using Halophilic Fungi
}

\author{
Priya AK, M. Nithya, B. Dinesh, J.Bajan Singh
}

\begin{abstract}
Nowadays contamination due to perilous materials, for instance, wonderful steel has redesign into one of the maximum essential authentic natural issues and famous medical problem. Cleaning of such substances from soil and water has been an extremely good risk. Biomaterial, for example, organisms, yeast and inexperienced boom has turn out to be a charge effectivesolution for wastewater containing low fixation huge metals. The effect of $\mathrm{pH}$, temperature, beginning fixation, touch time, and biosorbent measurements on biosorption restrict is studied.All tried growths showed slight to immoderate adsorption of overwhelming metals, amongst which Aspergillus flavus, Aspergillus restrictus and Sterigmatomyceshalophilusshowed the pleasant normal adsorption of each terrific metallic taken into consideration, with a everyday of ninety, 80 four and eighty five\%, one after the opposite. The biosorption manner obeys Freundlich and the Langmuir adsorption isotherms. This contemporary research paintings of biosorption by using halophilic organisms utilising low-cost media for expulsion of big metals gives a financially savvy ecological arrangement. Brightening of the arrangement of metallic take-up is an actual take a look at inside the area of biosorption.
\end{abstract}

Keywords:Ecological troubles, Biosorption, Fungi, Yeast and Algae, Heavy Metals.

\section{INTRODUCTION} make more and more natural impact in recent times. Overwhelming metals are normally occurring additives that can be observed throughout the sector. Because of anthropogenic wearing activities, as an example, current method, fabricating process, mining, nearby waste switch and so forth., overwhelming metals is arranged into the earth and activates first-rate steel harming (Priya and Nagan, 2015b).Even in follows huge metals are poisonous to every verdure. Due to its lethality, gradual addition in biomaterials and decided homes it makes extreme infection (Tam and Wong, 2000). This is not correctly corrupted with the aid of every artificial and herbal manner, may additionally moreover preserve going for broadened time within the earth. Severa techniques were diagnosed for the expulsion of overwhelming metals from infected supply, as an instance, precipitation, dissipation, particle change, movie paperwork, and so forth. However, a few demanding situations arise due

Revised Manuscript Received on September 14, 2019.

Priya AK, Associate Professor, Department of Civil Engineering, KPR Institute of Engineering and Technology, Coimbatore, Tamil Nadu, India. (Email: akpriy@gmail.com)

M. Nithya, Professor, Department of Civil Engineering, Siddhartha Institute of Technology and Sciences, Hyderabad, Telangana, India.

B. Dinesh, Assistant Professor, Department of Civil Engineering, Siddhartha Institute of Technology and Sciences, Hyderabad, Telangana, India.

J. Bajan Singh, Assistant Professor, Department of Civil Engineering, Siddhartha Institute of Technology and Sciences, Hyderabad, Telangana, India.
Hazardous materials, for example, overwhelming metals

to execution of these techniques, for example, unexpected side-effect association, abundance synthetic use, advent of dangerous slop and so on. Biosorption is biotechnology innovation and a savvy approach for large steel expulsion from inflamed source (Priya and Nagan, 2015a). Stay or dead microorganisms or their subsidiary are applied as a biosorbent for compelling steel adsorption. Existence form, for instance, microscopic organisms, parasites, yeast and plant life are seen as capable in accumulating substantial metals from wastewater.Microorganisms are basically disengaged from hypersaline environment and can increase in vitro in saline situation and named as halophilic microorganisms (Ali et al., 2016a).The existing work manner to ponder the expulsion of overwhelming metals from wastewater utilising minimal strive, very capable lively biosorption device making use of halophilic growths. The capability of parasites as a biosorbent for the evacuation widespread metals modified into considered and effect of numerous handled strategies on steel take-up at diverse $\mathrm{pH}$ esteems have become likewise contemplated.

\section{SUBSTANCES AND STRATEGIES}

\subsection{Isolation and enhancement of organisms}

In this exam organisms have been restricted from tannery waterwater near Madurai. This growths includesAspergillus flavus, Aspergillus restrictus andSterigmatomyces halophilus. Aspergillus flavus changed into evolved in five $\%$ of $\mathrm{Nacl}$ and distinctive organisms required $10 \%$ of Nacl in Potato dextrose soup (PDB) and in medium.The growths have been constrained and vaccinated in PDB with $500 \mathrm{mg} / \mathrm{L}$ of metal fixation. The boxes were hatched for 10 days at research center temperatures along manipulate medium with out a contagious strain. The biomass had been completed from the PDB via sifting through Whatman channel paper and filtrate end up amassed and dried for medium-term in a selection at eighty ${ }^{\circ} \mathrm{C}$ and the dry weight changed into anticipated (Jaeckel et al., 2005).

\subsection{Acid processing method}

The method from the united states Environmental protection agency (EPA, 1996) was utilized with the essentialvariations. Round zero. $2 \mathrm{mg}$ of dried contagious examples wastaken in a $100 \mathrm{~mL}$ Erlenmeyer funnel normal flagon. $20 \mathrm{~mL}$ of sixty five $\% \mathrm{HNO} 3$ and $3 \mathrm{~mL}$ of deionised (DI) water modified into added to each cup and mounted dim room. After $24 \mathrm{~h}$, the cups were warmed on a hot plate at one zero five ${ }^{\circ} \mathrm{C}$. Similarly it modified into warmed via together with $10 \mathrm{~mL}$ of $35 \% \mathrm{HCl}$ until no reaction with the 
corrosive become watched. At that factor the examples were processed for 1 hrby reflux. Subsequent to cooling, $3 \mathrm{~mL}$ of $30 \% \mathrm{H} 2 \mathrm{O} 2$ turned into delivered to each instance and the temperature end up elevated to one zero five ${ }^{\circ} \mathrm{C}$ until the blends were given vapid. Within the wake of cooling, the processed arrangements have been sifted through channel paper through endured washing to expel the insoluble particles and thenmakeup to a closing quantity of $50 \mathrm{~mL}$ with DI water.

\section{Three Batch tries through way of shaking jar situation}

Whilst the parasites areintroduced in a metallic affiliation, biosorption of metal particle on increase will seem. The overpowering metal particle in association will decay until a balance esteem is come to. The time required for the technique is the stability time. The effect of $\mathrm{pH}$ at the concord time for biosorption of $\mathrm{Cd}, \mathrm{Cu}$, and $\mathrm{Zn}$ debris end up considered making use of $\mathrm{pH}$ estimations of 6.Zero, 7.0, eight.Zero and 9.Zero. Those qualities had been considered at the same time as assessments, and no majorchange in $\mathrm{pH}$ esteems became examined.In preliminaries, underneath $3 \mathrm{~mL}$ of parasitic traces had been immunized into $100 \mathrm{~mL}$ metallic arrangement and installed shaking nation of a hundred thirty rpm the usage of orbital shaker (Priya and Nagan, 2015a). One of a kind remedy preliminaries have been completed with the aid of changing the existence shape and convergence of metal particle association. Three $\mathrm{mL}$ inoculum is regular depending on its turbidity, if turbid nature builds the productivity steadily diminishes. Subsequently the efficient organisms changed into outstanding and applied in the bioreactor contemplates (Priya and Nagan, 2015b).

\section{CONSEQUENCES AND VERBAL EXCHANGE \& RESULTS}

The metals which deliver extra thickness than water are taken into consideration as overwhelming metals. Their lower popularity can assist particular existence sports. Modern introduction has delivered alarming ranges of defilement through overwhelming metals in soil and water (He et al., 2005). In parasites, the protein oxidases can be lively by means of copper(Guill_en and Machuca, 2008). The restriction of copper $(\mathrm{Cu})$ to effectively permit and provide electrons, its critical job in oxidation-decrease (redox) responses and in rummaging unfastened radicals. Aspergillus flavus, Aspergillus restrictus and Sterigmatomyces halophiluswere evaluated to ingest the $\mathrm{Cu}$ extensively, with an excellentquantity of improvement is also appeared in parent $1 . \mathrm{Cu}$ has been accounted for preceding restriction contagious enlargement (Nasim et al., 2008). In another exam, it changed into placed that $\mathrm{Cu}$ intensified the causticity of parasitic improvement medium (Guill_en and Machuca, 2008), which from time to time falls brief for the ones halophiles to develop, as they increase in a soluble medium (Ali et al., 2013a).Cadmium (Cd) is regarded as deadly to existence and in biogeochemical cycles. Figure 2 indicates that a. Flavus and S. Halophilus have been resolved to reduceprominent centralization of $\mathrm{Cd}$. The relaxation of the parasites in this investigation consumed $\mathrm{Cd}$ usually. While all is stated in finished, $\mathrm{Cd}$ to suffocate the improvement of
microorganisms.Zinc (Zn) assumes a essential procedure in protein amalgamation, insusceptible frameworks and within the cell department of microorganisms. But, in greater noteworthy sum, it's miles deadly for dwelling beings and makes to expose an antifungal cause (Savi et al., 2013). All organisms in Figure3 show excessive absorbance of $\mathrm{Zn}$. A. Gracilis and S.Halophilusboth show over eighty two\% evacuation of $\mathrm{Zn}$ on this studies.

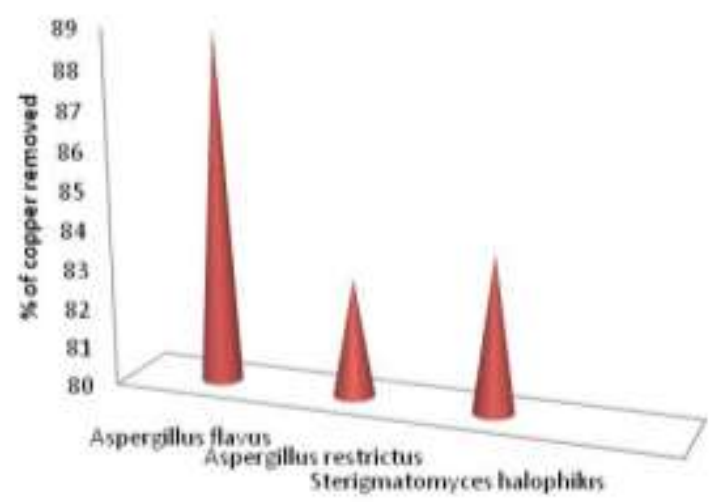

Figure 1. Percentage of copper removed by each halophilic fungi

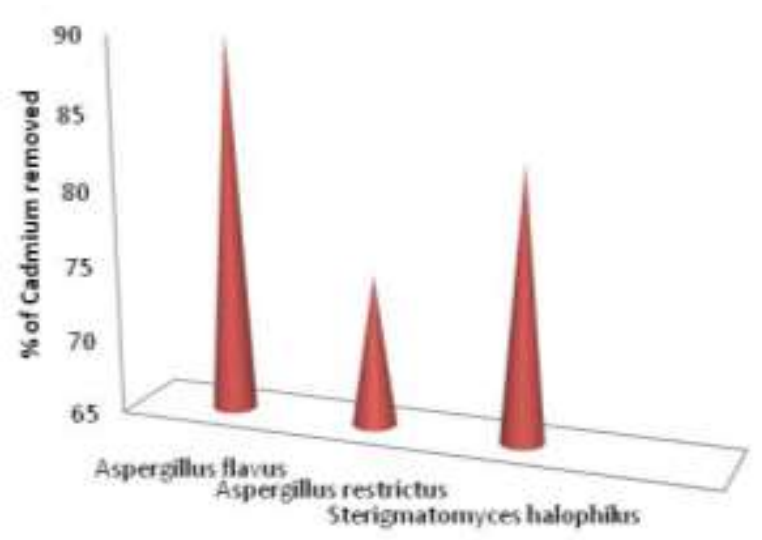

Figure 2. Percentage of cadmium removed by each halophilic fungi

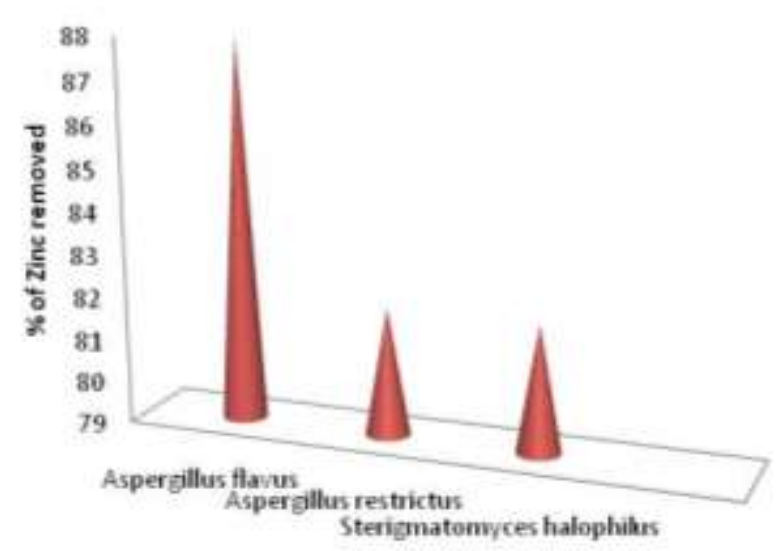

Figure 3. Percentage of Zinc removed by each halophilic fungi

Blue Eyes Intelligence Engineering 
The extensive majority of the investigation indicated firstrate consequences in overwhelming metallic ingestion by means of utilising parasites yet around all have applied shake jar societies along Sabouraud Dextrose Broth (Ahmad et al., 2006; Faryal et al., 2007; Dacera and Babel, 2008), By utilizing potatoes, PDB can without difficulty be made in the lab (Hu et al., 2017). In view of this exam with recognize to ecofriendly makes use of of halophilic parasites (Ali et al., 2014a, 2014c, 2015), it's been expected that those growths may additionally display better evacuation; effectiveness of overwhelming metals contrasted with normal organisms due to their preference forlive in hypersaline circumstance just as in little water movement (Ali et al., 2013b, 2016a), that's one of the attributes of wastewater (Ali et al., 2014a).

From this exam, A. Flavus validated the brilliant expulsion effectiveness of vast metal with an estimation of around $90 \%$, trailed with the aid of $85 \%$ for S. Halophilus. A. Flavusgrows nicely and suggests higher expulsion contrast with different growths. Simultaneously A .Flavus develop in 5\% grouping of $\mathrm{NaCl}$ (Ali et al., 2013a), which may be a motive for its transcendent development and takes out anadequatequantity of overwhelming metallic from metal particle association. This suggests the excessive saline circumstance may additionally activateenhanced execution in halophilic organisms for overwhelming metallic retention. $\mathrm{S}$. Halophilus, as halophilic yeast shows more expulsion effectiveness than maximum filamentous growths. This research results coordinate with Machado et al. (2008), who immunized Saccharomyces cerevisiae for the overwhelming metals evacuation via bioremediation method, which achievedbetter productiveness in low water development.

\section{IV.CONCLUSION}

Microscopic organisms is a functioning and compelling microorganisms to expulsion massive metals likewise parasites similarly shows higher effectiveness in evacuating overwhelming metals by means of growing mass improvement in medium.Therefore, fungican be applied in remediation approach to decrease or expel massive metals from sullied environment.The take-up restriction of cadmium, copper, and zinc diminishes with increasing of biosorbentconcentration. The evacuation restrict increments with increasing $\mathrm{pH}$ and the maximum intense capacity esteems had been obtained at $\mathrm{pH}$ eight.Zero. The biosorption method obeys Freundlich and the Langmuir adsorption isotherms. The sorption electricity indicates the pseudo-2nd request fee reaction, moreover suggests the intraparticle dissemination are passed off in sorption process. Biosorption limit of organisms or yeast increments due to basic a pretreatment method that is seen as superior to other treatment.

The extraordinaryremoval effectiveness were given by using halophilic growths in this exam manages financially savvy solution for dirtied wastewater or soil. In this cutting edge global, nature authorizes new problems, looking forward to factor of hobby research to advance the skillability of parasites in situation. Contrast with regular adsorbents contagious biomass shows talented overwhelming metal evacuation limit. The growths based which isn't always financially savvy contrasted with PDB.

totally biosorption approach can be utilized as analternate of a contemporary steel expulsion innovation or may be utilized as a refining unit for present remedy unit.

\section{REFERENCES}

1. Ahmad, I., Ansari, M.I., Aqil, F., 2006. Biosorption of $\mathrm{Ni}, \mathrm{Cr}$ and $\mathrm{Cd}$ by way of metallic tolerant Aspergillus Niger and Penicillium sp. Utilizing single and multimetallic association. Indian J. Exp. Biol. 44, $73 \mathrm{e} 76$.

2. Ali, I., 2014. Seven essential difficulties for Pakistan-and the exercises they could coach. Futurist forty eight, $22 \mathrm{e} 26$.

3. Ali, I., Akbar, An., Anwar, M., Prasongsuk, S., Lotrakul, P., Punnapayak, H., 2015. Purging and portrayal of a polyextremophilic an amylase from a commit halophilic Aspergillus penicillioides detach and its capacity for dunk with cleansers. BioMed. Res. Int. 2015, eight. Https://doi.Org/10.1155/2015/245649. Article ID 245649.

4. Ali, I., Akbar, An., Anwar, M., Yanwisetpakdee, B., Prasongsuk, S., Lotrakul, P., Punnapayak, H., 2014a. Decontamination and portrayal of extracellular, polyextremophilic an amylase were given from halophilic Engyodontium series. Iran. J. Biotechnol. 12, $35 \mathrm{e} 40$.

5. Ali, I., Akbar, An., Aslam, M., Ullah, S., Anwar, M., Punnapayak, H., Lotrakul, P., Prasongsuk, S., Yanwisetpakdee, B., Permpornsakul, P., 2016a. Relative research of physical variables and microbial decent sort of 4 guy-made outrageous biological systems. Proc. Natl. Acad. Sci. India 86, 767e778.

6. Ali, I., Kanhayuwa, L., Rachdawong, S., Rakshit, S.K., 2013a. Recognizable proof, phylogenetic exam and portrayal of dedicate halophilic growths disengaged from a person-made daylight primarily based saltern in Phetchaburi location, Thailand. Ann. Microbiol. 63, $887 \mathrm{e} 895$.

7. Ali, I., Siwarungson, N., Punnapayak, H., Lotrakul, P., Prasongsuk, S., Bankeeree, W., Rakshit, S.K., 2014c. Screening of ability biotechnological programs from commit halophilic parasites, separated from a man-made daylight primarily based saltern located in Phetchaburi region, Thailand. Pakistan J. Bot. 46, 983e988.

8. Dacera, D., Babel, S., 2008. Expulsion of overwhelming metals from tainted sewage ooze using Aspergillus Niger elderly crude fluid from pineapple squanders. Bioresour. Technol. 99, 1682e1689.

9. Faryal, R., Sultan, A., Tahir, F., Ahmed, S., Hameed, A., 2007. Biosorption of lead with the aid of indigenous parasitic lines. Pakistan J. Bot. 39, 615e622.

10. Guill_en, Y., Machuca, A., 2008. The effect of copper at the development of wood-decaying organisms and a blue-recolor growth. World J. Microbiol. Biotechnol. 24, $31 \mathrm{e} 37$.

11. He, Z.L., Yang, X.E., Stoffella, P.J., 2005. Follow components in agroecosystems and affects on nature. J. Follow Elem. Drug. Biol. 19, 125e140.

12. Hu, L., Wan, J., Zeng, G.M., Chen, A.W., Chen, G.Q., Huang, Z., He, K., Cheng, M., Zhou, C., Xiong, W., Lai, C., Xu, P., 2017. Exhaustive assessment of the cytotoxicity of $\mathrm{CdSe} / \mathrm{ZnS}$ quantum dabs in Phanerochaetechrysosporium by way of mobile take-up and oxidative stress. Environ. Sci. Nano. Https://doi.Org/10.1039/c7en00517b. 
13. Hu, L., Wan, J., Zeng, G.M., Chen, A.W., Chen, G.Q., Huang, Z., He, K., Cheng, M., Zhou, C., Xiong, W., Lai, C., Xu, P., 2017. Exhaustive evaluation of the cytotoxicity of $\mathrm{CdSe} / \mathrm{ZnS}$ quantum spots in Phanerochaetechrysosporium by using cell take-up and oxidative stress. Environ. Sci. Nano. Https://doi.Org/10.1039/c7en00517b.

14. Huang, C., Zeng, G.M., Huang, D.L., Lai, C., Xu, P., Zhang, C., Cheng, M., Wan, J., Hu, L., Zhang, Y., 2017. Impact of Phanerochaetechrysosporium vaccination on bacterialcommunity and steel adjustment in lead-defiled rural wastecomposting. Bioresour. Technol. 243, 294e303.

15. Jaeckel, P., Krauss, G.J., Krauss, G., 2005. Cadmium and zinc reaction of the growths Heliscuslugdunensis and Verticillium cf. Alboatrum secluded from profoundly contaminated water. Sci. All out Environ. 346, 274e279.

16. Machado, M.D., Santos, M.S.F., Gouveia, C., Soares, H.M.V.M., Soares, E.V., 2008. Expulsion of overwhelming metals utilising a brewer's yeast pressure of Saccharomyces cerevisiae: the flocculation as a department process. Bioresour. Technol. 99, 2107e2115.

17. Nasim, G., Ilyas, N., Ali, A., Munawar, A., 2008. Impact of salt making ready on in vitro improvement of a few dust growths. Pakistan J. Bot. 40, 427e431.

18. Priya AK \&Nagan S, 2015a, "Bioremediation of Dye Effluent and Metal Contaminated Soil: Low-Cost Method for Environmental Clean up with the aid of Microbes", J Environ. Science \&Engg. Vol. 57, No. 2, p. 109-119.

19. Priya AK \&Nagan S, 2015b, "Remediation of Heavy Metals from Electroplating Effluent making use of bacterial Strains in Up circulate Immobilized Column Reactor", Journal of Pure and Applied Microbiology, vol.9, no.2, pp. 1411-1416.

20. Savi, G.D., Bortoluzzi, A.J., Scussel, V.M., 2013. Antifungal properties of Zinccompounds against toxigenic parasites and mycotoxin. Int. J. Nourishment Sci. Technol. Forty eight, 1834e1840. 